\title{
A Retinal Circuit That Computes Object Motion
}

\author{
Stephen A. Baccus, ${ }^{1,2}$ Bence P. Ölveczky, ${ }^{1}$ Mihai Manu, ${ }^{2}$ and Markus Meister ${ }^{1}$ \\ ${ }^{1}$ Department of Molecular and Cellular Biology and Center for Brain Science, Harvard University, Cambridge, Massachusetts 02138, and ${ }^{2}$ Department of \\ Neurobiology, Stanford University School of Medicine, Stanford, California 94305
}

Certain ganglion cells in the retina respond sensitively to differential motion between the receptive field center and surround, as produced by an object moving over the background, but are strongly suppressed by global image motion, as produced by the observer's head or eye movements. We investigated the circuit basis for this object motion sensitive (OMS) response by recording intracellularly from all classes of retinal interneurons while simultaneously recording the spiking output of many ganglion cells. Fast, transient bipolar cells respond linearly to motion in the receptive field center. The synaptic output from their terminals is rectified and then pooled by the OMS ganglion cell. A type of polyaxonal amacrine cell is driven by motion in the surround, again via pooling of rectified inputs, but from a different set of bipolar cell terminals. By direct intracellular current injection, we found that these polyaxonal amacrine cells selectively suppress the synaptic input of OMS ganglion cells. A quantitative model of these circuit elements and their interactions explains how an important visual computation is accomplished by retinal neurons and synapses.

Key words: neural coding; eye movements; motion processing; computational model; neural circuit; inhibition

\section{Introduction}

The retina has about a dozen types of output neurons. Each type of retinal ganglion cell forms a complete array that covers the visual field (Masland, 2001). Every such population represents a specific computation on the raw visual image, and transmits the resulting output image to various stations in the brain. To understand the function of the retina, one would like to identify for each ganglion cell type what image operation it reports. Then, one needs to examine how that computation is performed by the circuits of interneurons between photoreceptors and ganglion cells. Recently we described a class of retinal ganglion cells involved in an ecologically important visual computation: the detection of moving objects (Ölveczky et al., 2003). Here we report how this specific computation is accomplished through the interactions of certain bipolar, amacrine, and ganglion cells.

Image motion on the retina has two components: one, of course, is the movement of objects in the scene. The other is observer-induced motion, resulting from translation of the animal, movements of the head, large gaze-shifting eye movements, and the incessant small eye movements that persist even during gaze fixations (Skavenski et al., 1979; Engbert and Kliegl, 2004). As a result of observer or eye motion, even a static scene moves across the retina continuously, with a motion trajectory that is nearly uniform over large parts of the image. An object moving relative to the background causes a patch of image on the retina to

Received Sept. 13, 2007; revised April 1, 2008; accepted April 24, 2008.

This work was supported by a National Research Service Award postdoctoral fellowship (S.A.B.), a Harvard Junior Fellowship (B.P.O.), and grants from the National Institutes of Health (S.A.B., M. Meister).

Correspondence should be addressed to Stephen A. Baccus, Department of Neurobiology, Stanford University School of Medicine, 299 West Campus Drive, Stanford, CA 94305. E-mail: baccus@stanford.edu.

B. P. Ölveczky's present address: Department of Organismic and Evolutionary Biology and Center for Brain Science, Harvard University, 16 Divinity Avenue, Cambridge, MA 02138.

DOI:10.1523/JNEUROSCI.4206-07.2008

Copyright $\odot 2008$ Society for Neuroscience $\quad$ 0270-6474/08/286807-11\$15.00/0 move with a trajectory different from that in a large surrounding region. A neuron designed to detect and flag a moving object in the retinal image should therefore have the following desirable properties: it should monitor a patch of image and fire when that patch moves differently from the surrounding region. Furthermore, to allow the tagging of all kinds of objects, the neuron should produce this response regardless of the visual pattern displayed in its image patch or in the surrounding region. Finally, to accommodate all kinds of observer motion, the neuron's response should be independent of the direction of image motion. Remarkably, these capabilities are found in certain types of retinal ganglion cells (Ölveczky et al., 2003), termed "object motion sensitive (OMS)" (see Fig. 1).

The OMS neurons meet two seemingly conflicting requirements: they are highly tuned to a condition of differential motion between the receptive field center and the surround, but at the same time remarkably insensitive to the actual visual pattern in the center or the surround. Here we explore how this is accomplished, by recording directly from many interneurons in the retina. This approach allowed us to trace the flow of signals during the differential motion computation, identify which specific retinal interneurons are involved, and verify their connectivity.

\section{Materials and Methods}

Electrophysiology. Simultaneous intracellular and multielectrode recording was performed as described previously (Baccus and Meister, 2002). The isolated retina of a tiger salamander was placed on a flat array of 61 extracellular electrodes and held in place under a layer of $0.6 \%$ agarose (type III-A: High EEO; Sigma) of $\sim 100 \mu \mathrm{m}$ thickness with a dialysis membrane containing several 150-300 $\mu \mathrm{m}$ holes. Sharp intracellular microelectrodes were positioned over the retina under infrared illumination, viewed through an infrared-sensitive CCD camera, and guided through the dialysis membrane and agarose into the retina. Electrodes were filled with $2 \mathrm{~m}$ potassium acetate and 1\% Alexa Fluor 488, with a final impedance of $150-250 \mathrm{M} \Omega$. 
Intracellular recordings were made from a total of 22 bipolar cells (resting membrane potential ranging between -45 and $-55 \mathrm{mV}$ ), 4 horizontal cells ( -40 to $-50 \mathrm{mV}$ ), 12 OMS ganglion cells ( -60 to -70 $\mathrm{mV}), 21$ polyaxonal amacrine cells $(-55$ to $-65 \mathrm{mV}$ ), and 14 amacrine cells of other types, including slow ON-OFF cells, ON cells, and OFF cells $(-50$ to $-65 \mathrm{mV})$. Not all stimuli were presented to all cells. The soma of each neuron was situated in the center of the "object region" of the stimulus, which was more than twice as large as the receptive field centers of the bipolar, amacrine, and ganglion cells from which we recorded. A cell was identified during the experiment by its response to flashes and global motion and differential motion stimuli. After the recording session, the neuron was filled with dye iontophoretically, and the cell type was confirmed by imaging in the live preparation using a $40 \times$ waterimmersion objective. Selected neurons were micrographed using a CCD camera and their processes traced from three-dimensional image stacks.

Cell nomenclature. The five major classes of retinal neurons can be recognized unambiguously. Within each class there exists a wide range of cell shapes and physiological properties, and it is thought that these reflect discrete genetic types of neuron. In the salamander retina, the anatomical and physiological properties of these cells tend to form a continuum rather than breaking naturally into discrete clusters. Therefore the type designations can vary according to the methods applied. For the major neurons involved in the circuit described here, we provide anatomical tracings, receptive fields, and light responses to standard stimuli (see Figs. 2, 3, 6) by which they may be recognized. In addition we give here some correspondence to type designations used previously. The OMS ganglion cells are the "fast OFF" cell of Warland et al. (1997), the "biphasic OFF" cell of Segev et al. (2006), and resemble the "small highly complex" morphological type of Costa and Velte (1999). The OFF bipolar cells with rapid kinetics (see Figs. 2-4) resemble "type 5" of Wu et al. (2000). The polyaxonal amacrine cells identified in this study are distinct from other amacrines by having a field of axons that spreads laterally over several millimeters, whereas the dendrites and consequently the receptive field are constrained to a radius of $\sim 200 \mu \mathrm{m}$ (see Fig. 2) (see also Ölveczky et al., 2003). Their light response is OFF dominated. Their correspondence to the literature is uncertain; many reports mention wide-field amacrine cells in the salamander retina, but their images are mostly from vertical sections, which obscures the distinctive morphology.

Visual stimulation. Visual stimuli were projected onto the retina from a video monitor, at a photopic mean intensity of $\sim 8 \mathrm{~mW} / \mathrm{m}^{2}$. The circular object region was $800 \mu \mathrm{m}$ in diameter, and the background region measured $5900 \times 4400 \mu \mathrm{m}$. The two regions were separated by a $92 \mu \mathrm{m}$ gray annulus, although this annulus is not required for differential motion selectivity (Ölveczky et al., 2003). The eye movement during fixational drift resembles a random walk (Skavenski et al., 1979; Engbert and Kliegl, 2004), with horizontal and vertical motion occurring independently. Statistics of these eye movements are qualitatively similar across species, including humans and salamander (Manteuffel et al., 1977; Engbert and Kliegl, 2004). To approximate the trajectory of fixational drift, grating stimuli consisting of black and white bars with a periodicity of $184 \mu \mathrm{m}$ were jittered in one dimension. The trajectory was generated by stepping the grating randomly every $15 \mathrm{~ms}$ with a step size of $9.2 \mu \mathrm{m}$. In the global motion condition, the seeds for generating the random walk were the same for the object and background regions, producing the same motion trajectory in both regions. In the differential motion condition, the seeds were different for the object and background regions. In the local motion condition, the background region was gray. To map receptive fields, the stimulus was a randomly flickering checkerboard, with square fields $18-92 \mu \mathrm{m}$ in width, each modulated independently by white noise (Meister et al., 1994).

Analysis and simulation. The spatiotemporal receptive field of a bipolar cell was computed from the response to random checkerboard stimulation by the standard method of reverse correlation:

$$
F(x, y, \tau)=\int^{T} s(x, y, t-\tau) b(t) d t
$$

where $F(x, y, \tau)$ is the linear response kernel of the bipolar cell at position $(x, y)$ and delay $\tau ; s(x, y, t)$ is the stimulus intensity at position $(x, y)$ and time $t$, normalized to zero mean and unit variance; $b(t)$ is the membrane potential of the bipolar cell; and $T$ is the duration of the recording. To predict the bipolar cell response to a jittering grating, the spatiotemporal filter, $F(x, y, \tau)$, was convolved with the stimulus, yielding the predicted response

$$
b^{\prime}(t)=\int^{T} s(x, y, \tau) \alpha F(x, y, t-\tau) d x d y d \tau
$$

where $\alpha$ is a scaling factor set to yield the best prediction. To predict the OMS ganglion cell response from measured bipolar cell responses, we postulated a simple nonlinear transformation followed by integration over many bipolar cells (see Fig. $4 D$ ):

$$
g^{\prime}(t)=\sum_{\phi} N\left(b_{\phi}(t)\right)
$$

where $g^{\prime}(t)$ is the predicted membrane potential of the ganglion cell; $b_{\phi}(t)$ is the membrane potential of a bipolar cell at phase $\phi$ relative to the grating; and $N(b)$ is a nonlinear transformation of the bipolar cell output.

Bipolar cell responses $b_{\phi}(t)$ were recorded using at least four equally spaced phases of the grating. The nonlinearity $N(b)$ consisted of a piecewise linear fit through five points, adjusted so that the prediction $g^{\prime}(t)$ most closely approximated the measured ganglion cell response.

To predict the OMS ganglion cell response to local motion (see Fig. 5) or the polyaxonal amacrine response to background motion (see Fig. 9) directly from the stimulus, the bipolar cell responses were predicted for each spatial phase, passed through the nonlinearity, and then summed:

$$
\begin{aligned}
g^{\prime}(t) & =\sum_{\phi} N\left(b^{\prime}{ }_{\phi}(t)\right) \\
& =\sum_{\phi} N\left(\int_{0}^{T} s(x, y, \tau) \alpha F_{\phi}(x, y, t-\tau) d x d y d \tau\right) .
\end{aligned}
$$

Judging from the receptive field sizes (see Fig. 2), an OMS ganglion cell receives input from at least 20 bipolar cells. For the simulation of Equation 4 , we therefore replicated the measured bipolar cell receptive field $F_{\phi}(x, y, t-\tau)$ at 20 different spatial phases relative to the grating. Although the actual number of contributing bipolar cells may well be larger, a finer phase spacing makes little difference for the predicted OMS response.

To characterize the speed tuning of a bipolar cell, we estimated its linear response to a grating stimulus ( $184 \mu \mathrm{m}$ period) moving at constant speed, by filtering the stimulus with the cell's spatiotemporal receptive field (Eq. 2). This generated a periodic output, whose amplitude was taken as the cell's sensitivity at that speed. The high-speed cutoff was defined as the speed at which the sensitivity fell to $90 \%$ of its peak value. Fast, transient OFF-type bipolar cells were identified from their receptive fields as those cells with a speed tuning cutoff of $>300 \mu \mathrm{m} / \mathrm{s}$ for a $184 \mu \mathrm{m}$ period grating.

To predict the OMS ganglion cell response to differential motion, the amacrine response was used to reduce the gain of the input to the rectification stage in the ganglion cell receptive field center,

$$
g^{\prime}(t)=\sum_{\phi} N\left(\frac{\int_{0}^{T} s(x, y, \tau) \alpha F_{\phi}(x, y, t-\tau) d x d y d \tau}{1+\beta a^{\prime}(t)}\right),
$$

where $a^{\prime}(t)$ is the amacrine cell potential scaled to range between a value of zero and one, and $\beta$ is an optimized gain factor. This best value of $\beta$ was found to be 1.04 , meaning that at times of greatest inhibition, the gain of the bipolar subunit input was reduced by a factor of 0.49 . This 

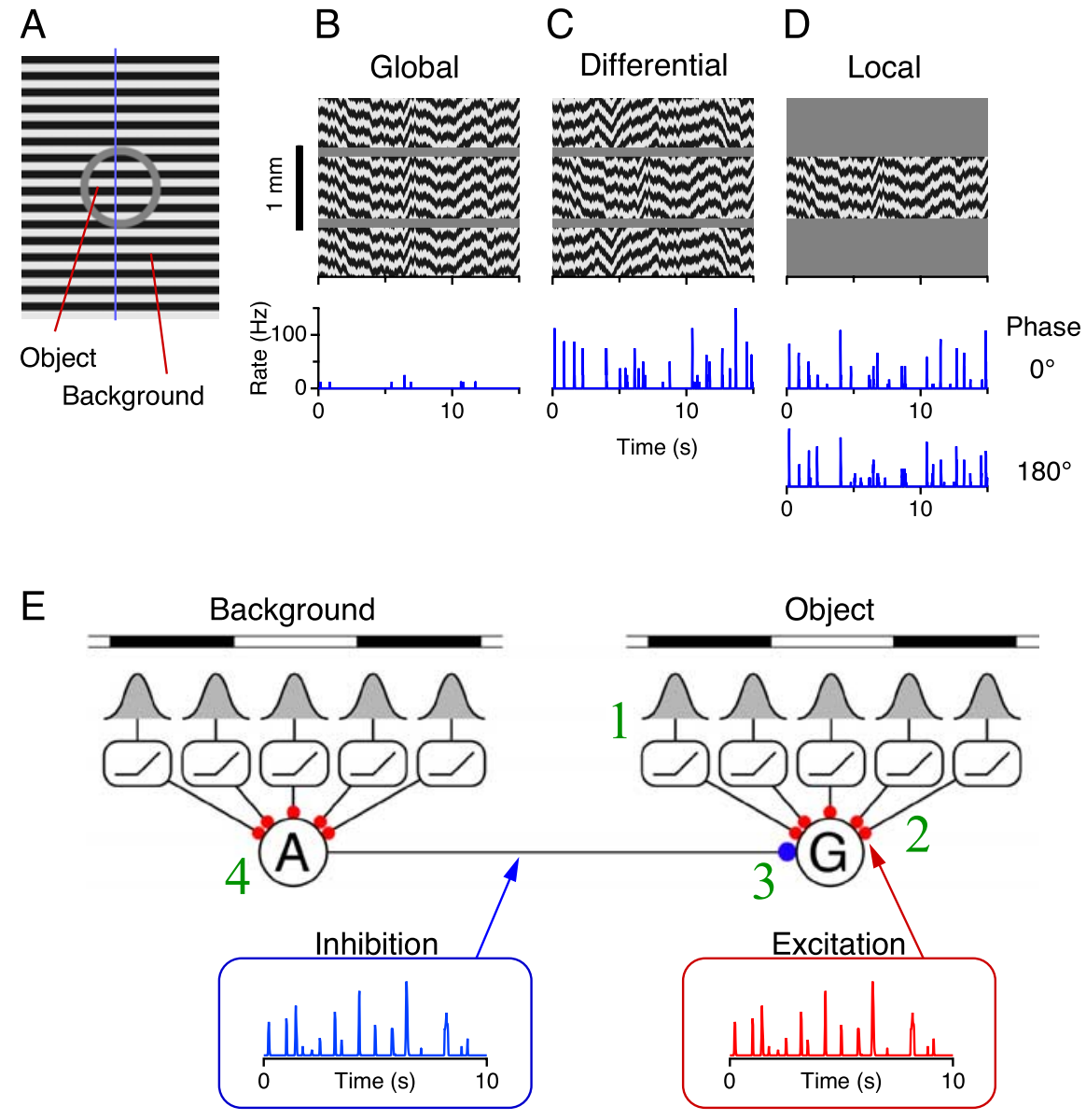

Figure 1. Stimuli and working model for studying the OMS circuit. $A$, Diagram of object and background regions in the stimulus display. $\boldsymbol{B}-\boldsymbol{D}$, First row, Space-time plot of a vertical cross section through the center of the stimulus (line in $\boldsymbol{A}$ ), showing trajectories for global motion, differential motion, and local motion. Second row, Firing rate of a sample OMS ganglion cell in response to 10 repeats of each stimulus sequence. Third row (D), Response to a local motion stimulus having the same trajectory but reversed grating phase $\left(180^{\circ}\right)$, with black and white bars exchanged relative to $0^{\circ}$ phase. $E$, Working model of the OMS circuit. An OMS ganglion cell (G) receives excitatory input in the object region from multiple small subunits. Each subunit applies a linear spatiotemporal filter to the stimulus in its receptive field. The result is then rectified and summed with the output of other subunits. An inhibitory amacrine cell (A) in the background region receives input from a similar set of rectified subunits. The output of the amacrine cell then inhibits the ganglion cell. Both inhibition and excitation are temporally sparse. Traces show the excitatory and inhibitory components of the model's response to global motion. Numbers identify the key circuit elements to be identified, as listed in the text.

divisive interaction of amacrine and bipolar input yielded a better fit than a subtractive interaction.

To compute correlation coefficients between actual and model membrane potential responses, spikes were removed by setting a threshold for the derivative of the membrane potential, and then each response was smoothed with a box filter of width $20 \mathrm{~ms}$. The correlation coefficient $r$ between two responses $x(t)$ and $y(t)$ was then calculated as

$$
r=\frac{\int_{0}^{T}(x(t)-\langle x\rangle)(y(t)-\langle y\rangle) d t}{\sqrt{\int_{0}^{T}(x(t)-\langle x\rangle)^{2} d t} \sqrt{\int_{0}^{T}(y(t)-\langle y\rangle)^{2} d t}}
$$

where $T$ is the duration of the experiment, and $\langle$... denotes the time average.

To measure the delay between amacrine and ganglion cell responses, we computed the cross-correlation $c(\tau)$ between two responses $a(t)$ and $g(t)$ as follows:

$$
c(\tau)=\int a(t) g(t+\tau) d t .
$$

The time of the peak of $c(\tau)$ was taken as the average delay between the two cells.

The receptive fields of amacrine cells were computed from random checkerboard stimulation as for bipolar cells (Eq. 1). For OMS ganglion cells, we used the spike train as the response variable instead of the membrane potential. The receptive field profiles in Figure 2 show the response kernel $F(x, y, \tau)$ at a time $\tau$ near the peak amplitude.

Averaged traces are computed across trials of identical stimuli.

\section{Results}

We presented to the isolated salamander retina visual stimuli with different combinations of object and background motion (Fig. 1). The display was divided into a central circular object region and a surrounding background region. Stripe gratings in each region were jittered in a random walk with the characteristics of drifting fixational eye movements (Manteuffel et al., 1977; Engbert and Kliegl, 2004), but limited to one dimension for simplicity. The jitter trajectories were chosen to produce three motion conditions (Fig. $1 B-D$ ): global motion simulated the image of a static scene scanned over the retina by fixational eye movements; differential motion simulated an object moving over a static background and scanned by eye movements; local motion was an artificial stimulus used to isolate the effects of the central object region. The motion trajectory of the object was identical in all three cases, and we recorded from OMS ganglion cells whose receptive field centers were contained in this object region. These neurons respond robustly to differential or local motion, but are nearly silent during global motion (Fig. $1 B-D$ ). Motion in the background has little effect on the response to the object (Fig. 1, differential vs local), unless its trajectory matches that of the object (Fig. 1, differential vs global), in which case it suppresses firing almost completely. Thus, the circuits of the retina must somehow compare the motion trajectories in the object and background regions, and the main challenge lies in finding how this is implemented.

\section{Working model of object motion circuitry}

In previous work (Ölveczky et al., 2003), the spiking response of OMS ganglion cells has been described by a computational model with several layers (Fig. 1E). The stimulus is first processed by linear subunits with a small receptive field and transient dynamics. In the next layer, the output from these subunits is strongly rectified and then summed within the object and within the background region. Finally, the output from the background inhibits the response to the object region.

OMS ganglion cells respond with nearly the same firing sequence regardless of the specific spatial pattern of the moving 
A

\section{Bipolar cell}

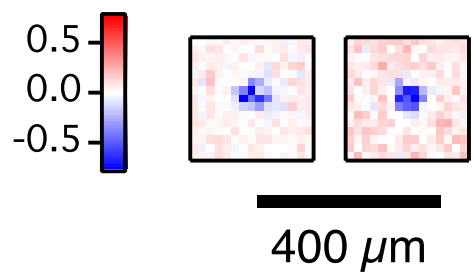

B ganglion cell

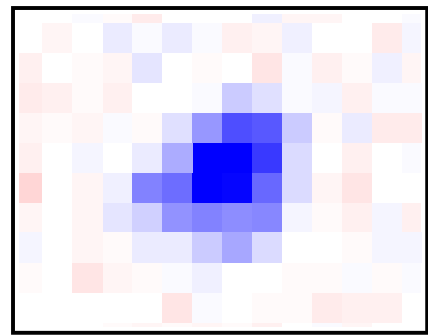

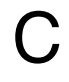

\section{Polyaxonal amacrine cell}

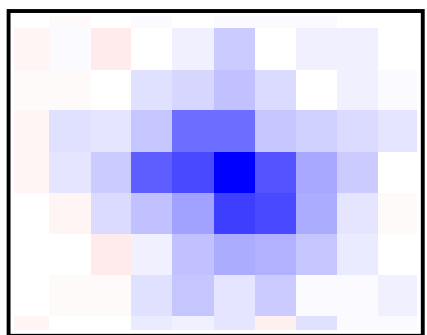

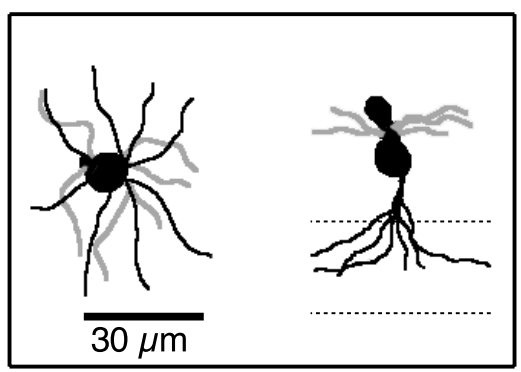
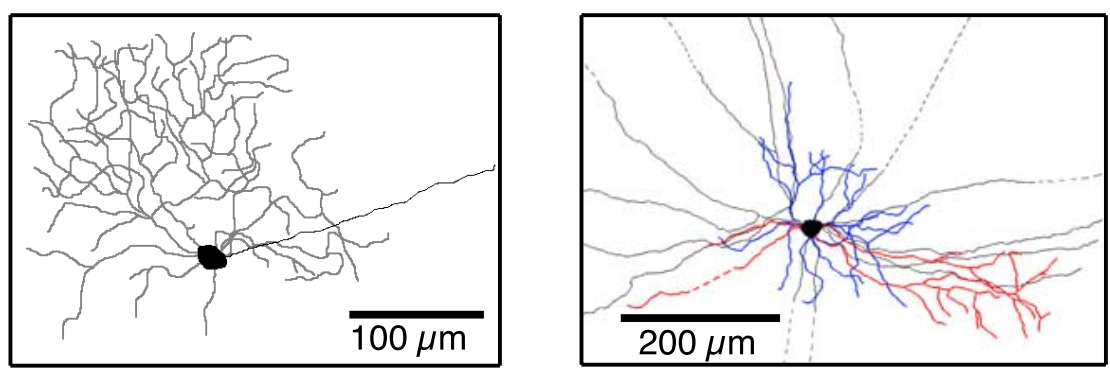

Figure 2. Receptive fields and morphology of relevant neurons. $\boldsymbol{A}$, Top, Spatial profile of the receptive field for two OFF bipolar cells; the same scale bar applies to receptive fields in $\boldsymbol{B}$ and $\boldsymbol{C}$. Bottom, Tracing of an OFF bipolar cell in tangential and radial views. Dotted lines indicate borders of the inner plexiform layer. The axon terminals ramify in the outer (OFF) sublamina. $\boldsymbol{B}$, Top, Receptive field of an OMS ganglion cell. Bottom, Tracing in tangential view. C, Top, Receptive field of a polyaxonal amacrine cell. Bottom, Tracing in tangential view showing $0 \mathrm{~N}$ dendrites (red), OFF dendrites (blue), and axons (black). Dashed lines indicate missing image information. The axons were followed beyond the pictured region and extended $>3 \mathrm{~mm}$ from the soma. Receptive fields and tracings are from different cells.

object. An example of this insensitivity to visual pattern can be observed by reversing the phase of the grating; swapping the black and the white bars has almost no effect on firing (Fig. $1 D$ ). Similarly, changing the period of the grating leaves the firing pattern virtually unchanged (Ölveczky et al., 2003). Such invariance to the spatial pattern of the stimulus can be understood as a direct consequence of the postulated summation over rectified subunits (Shapley and Victor, 1979; Ölveczky et al., 2003).

The second important computational property of the OMS circuit, selectivity for differential motion, arises in this model from the sparse nature of the neural signals (Fig. $1 E$ ). Both the excitation from the object region and the inhibition from the background region are delivered to the ganglion cell in a sparse sequence of transient pulses. If the background trajectory matches the object trajectory, then inhibition arrives coincident with excitation, silencing the ganglion cell. However, when the two trajectories are different, inhibition and excitation arrive at different times, and the ganglion cell fires.

Although this block diagram describes the response of the OMS ganglion cell accurately, it does not specify what neuronal circuit implements the computation. To test whether the retina indeed uses this algorithm and to flesh out the schematic with actual neural elements, one needs to answer the following questions (Fig. 1E): (1) What is the cellular identity of the subunits? (2) How is the output of these subunits integrated? (3) At what level is the signal from background motion combined with that from the object region? (4) What is the identity of the inhibitory cell that reports on the background motion?

\section{Basis of insensitivity to spatial pattern}

A key feature of the working model in Figure $1 E$ is the summation over small receptive field subunits. Based on recordings from mammalian ganglion cells, it has been proposed that these rectified subunits correspond to individual bipolar cells (Victor and Shapley, 1979; Demb et al., 2001).

\section{The role of bipolar cells}

To identify directly the subunits of the OMS ganglion cell, we recorded intracellular light responses from bipolar cells. First, we mapped each cell's spatiotemporal receptive field (see Materials and Methods). Bipolar cell spatial receptive fields measured 50$150 \mu \mathrm{m}$ in diameter (Fig. 2A). They were considerably smaller than those of OMS ganglion cells $(\sim 400 \mu \mathrm{m})$ (Fig. $2 B)$ or of the polyaxonal amacrine cells $(\sim 400 \mu \mathrm{m})$ (Fig. $2 C)$, interneurons that might mediate long-range inhibition (Ölveczky et al., 2003). In both the receptive field center and the antagonistic surround region, the bipolar cell's temporal filter followed a biphasic time course (Fig. 3A). The surround response was delayed and inverted in sign relative to the center.

When stimulated with a jittering grating, bipolar cells produced strong fluctuations in membrane potential, whose time course could be predicted accurately by passing the visual stimulus through each cell's measured spatiotemporal receptive field (Fig. $3 B$ ). The correlation coefficient between actual and predicted responses (see Materials and Methods) was $r=0.70 \pm 0.02$ ( 4 cells), nearly as large as the correlation between repeats of the identical stimulus $(r=0.78 \pm 0.05)$. Thus, in response to object motion that can be discriminated by OMS ganglion cells, these bipolar cells essentially applied a linear spatiotemporal filter to the stimulus. In particular, the voltage response changed sign when the phase of the jittering grating was reversed (Fig. $3 B$ ), unlike what happens in OMS ganglion cells (Fig. 1D). Clearly the characteristic of pattern invariance is not yet elaborated at the level of bipolar cells. 
A
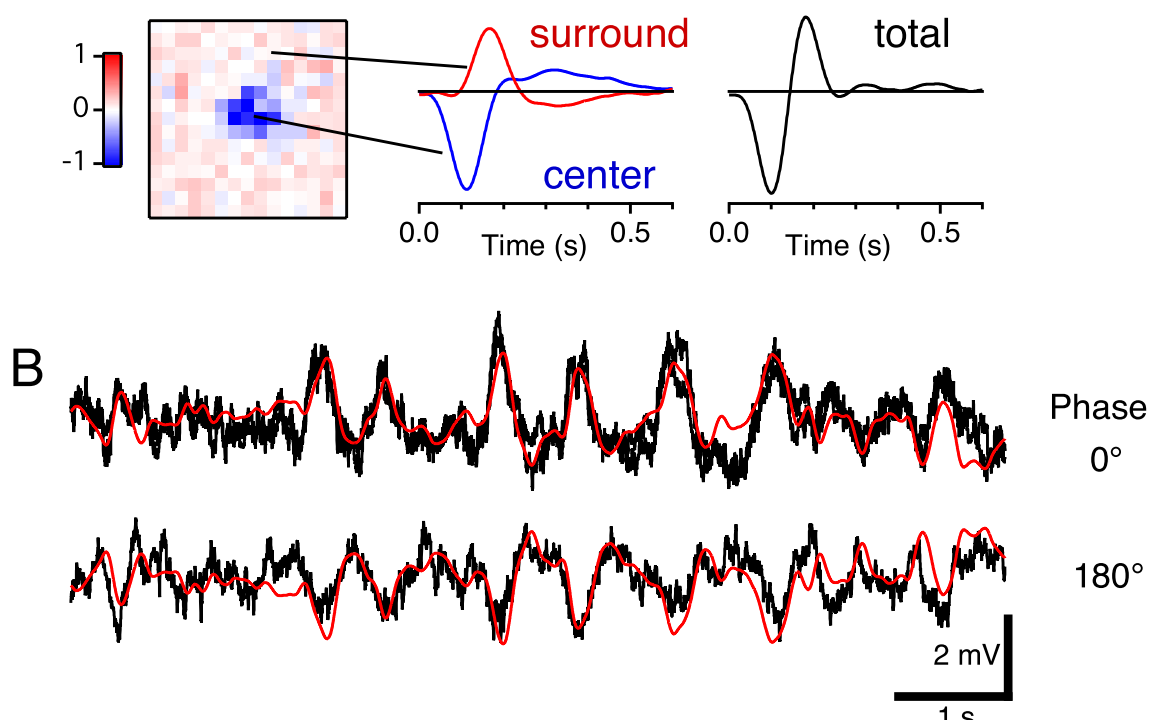

$180^{\circ}$

Figure 3. Bipolar cells encode the spatial pattern. $\boldsymbol{A}$, Bipolar cell spatiotemporal receptive field. Left, Spatial profile of a bipolar cell receptive field with OFF center and ON surround. Right, Temporal profile of the receptive field, normalized to the peak sensitivity, and summed over all pixels (total) or only pixels in the center or the surround. $\boldsymbol{B}$, Bipolar cell response to a jittering local motion stimulus. Top, Traces from two identical presentations of the same trajectory. Bottom, The same trajectory with the grating reversed ( $180^{\circ}$ spatial phase shift). Red line shows a prediction of the bipolar cell response generated from Equation 2 , using only the measured spatiotemporal receptive field and the stimulus trajectory.
We further investigated whether the transformation from bipolar response to ganglion cell response conformed to the rules of the OMS working model (Fig. $1 E$ ). We obtained bipolar cell responses at multiple positions relative to the jittering grating by recording from a single cell while repeating the grating's motion trajectory at different spatial positions, or phases (Fig. $4 A$ ). To predict the response of the OMS ganglion cell, these different bipolar cell responses were then individually rectified and summed (Fig. 4B). The shape of the rectifier function was calculated to optimally match the observed ganglion cell response (Fig. 4C). This resulted in a steep nonlinearity (Fig. 4D). The resulting sum of rectified bipolar signals closely approximated the intracellular responses recorded from OMS ganglion cells (Fig. 4C, see also Fig. 5).

The OMS ganglion cell response was found to be invariant to the spatial phase of the grating stimulus, not only at the level of spikes, but in its detailed subthreshold time course (Fig. 4C). The sum of rectified bipolar cell responses predicted many of those subthreshold fluctuations correctly. Given that the bipolar cell response still varies linearly with the stimulus (Fig. 4A), this rectification must happen after the bipolar cell soma, presumably in the process of transmission to the ganglion cell. Although the mechanism for rectification is unknown, it may involve the voltage dependence of calcium influx at the bipolar cell presynaptic terminal (Heidelberger and Matthews, 1992). If the mechanism is postsynaptic, it must be tightly localized in the ganglion cell dendrite, before many bipolar cell signals are summed across the dendritic tree.

\section{A refined subunit model}

By substituting concrete bipolar cells for the theoretical subunits, one obtains a refined model of the OMS ganglion cell response (Fig. 5) in which all parameters are derived from measurements. The stimulus is passed through the bipolar cell spatiotemporal receptive field, yielding predictions of responses in the population of bipolar cells. These responses are then rectified according to the measured bipolar-to-ganglion cell transformation, and the result is summed within the ganglion cell (Fig. 5A). This model matches the time course of the observed OMS ganglion cell response with remarkable accuracy (Fig. $5 B$ ): the predicted and observed response had a correlation coefficient of $r=0.65$ (see Materials and Methods), similar to the correlations between measured responses on repeats of an identical stimulus $(r=$ $0.71 \pm 0.02)$.

Not all bipolar cells produced a subunit model with this degree of accuracy. Indeed, the bipolar cells in our sample varied substantially in their spatiotemporal receptive fields. To characterize the receptive field in the context of moving grating stimuli, we computed for each bipolar cell the tuning curve for the speed of a steadily moving grating (see Materials and Methods). These tuning curves varied greatly in shape (Fig. 5C); in particular, the highest speed a neuron could track ranged from $<100 \mu \mathrm{m} / \mathrm{s}$ to $>400 \mu \mathrm{m} / \mathrm{s}$. We inserted each of these response types into the model of Figure $5 A$, and the resulting predictions for the OMS
Figure 4. The transformation from bipolar cells to OMS ganglion cell involves rectification and summation. $A$, Intracellular recordings from a single bipolar cell responding to a jittering local motion stimulus, with the grating positioned at four different phases. The top plot includes two traces for identical stimuli to illustrate reproducibility of the response. $\boldsymbol{B}$, The measured bipolar cell responses were each rectified (see $\boldsymbol{D}$ ) and then summed to yield a prediction for the ganglion cell response. $C$, Measured response of an $0 \mathrm{MS}$ ganglion cell to four phases of a jittering local motion stimulus. $\boldsymbol{D}$, The nonlinear function used to rectify the bipolar output. This shape was chosen to optimize the fit between the trace in $\boldsymbol{B}$ and the traces in $\boldsymbol{C}$ ignoring the action potentials. Vertical lines indicate action potentials of the ganglion cell. 


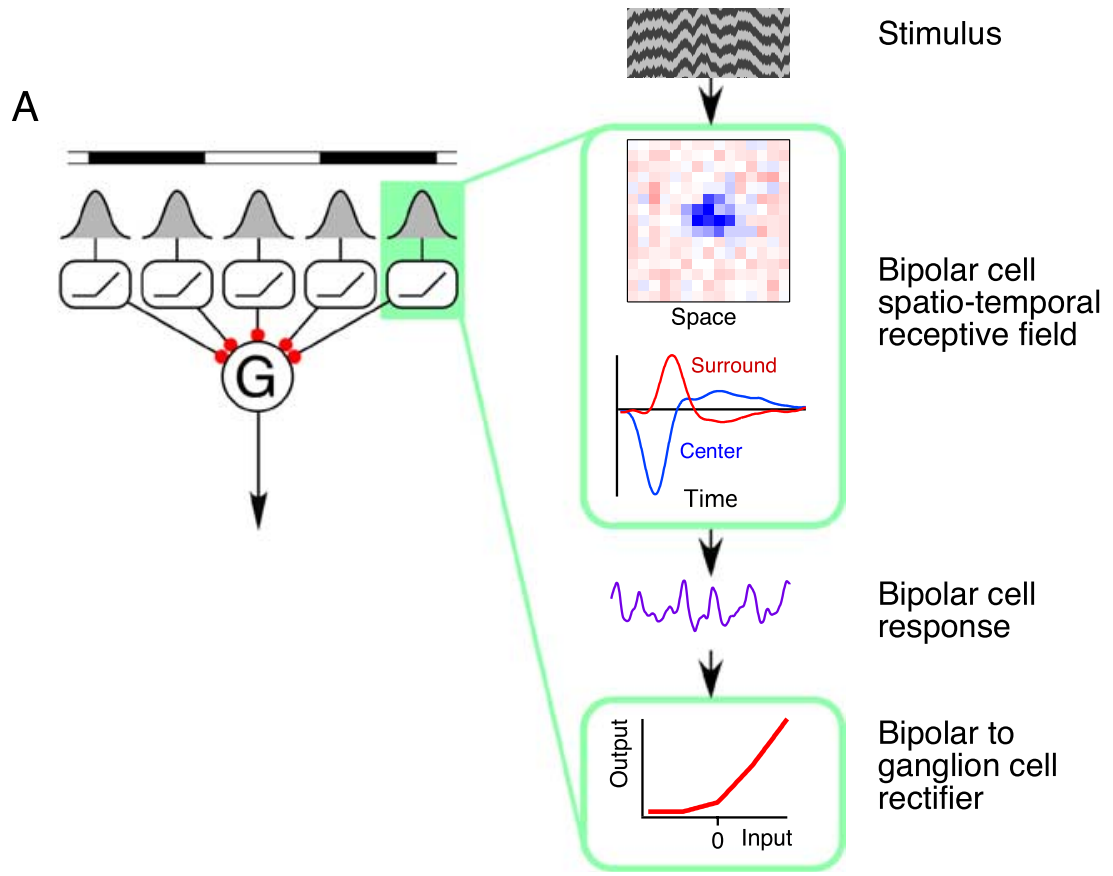

B OMS ganglion cell

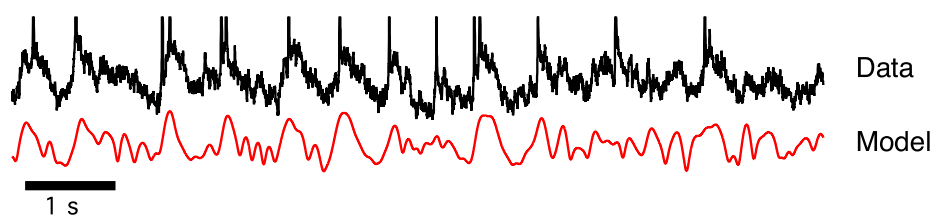

C Bipolar cell speed tuning

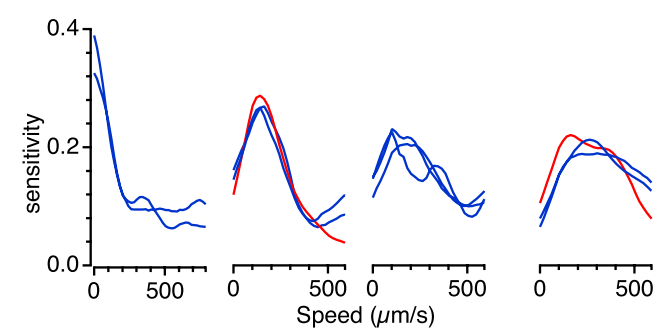

D Bipolar cells in OMS model

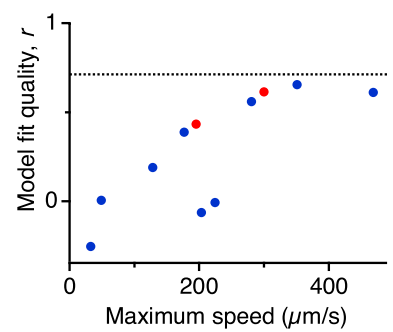

Figure 5. Model of the OMS ganglion cell excitatory input. $A$, Detailed structure of a subunit based on bipolar cell measurements. The stimulus trajectory of the object region during local motion is filtered by the bipolar cell spatiotemporal receptive field, yielding the bipolar cell response. Each bipolar response is then passed through the nonlinear transfer function from Figure $4 D$ and summed, yielding the ganglion cell membrane potential. $\boldsymbol{B}$, Comparison of ganglion cell membrane potential and model output. C, Speed tuning curves of bipolar cells to a moving $184 \mu \mathrm{m}$ period grating (see Materials and Methods). Each trace shows the normalized sensitivity from a different bipolar cell, grouped into four types of tuning profile. Cells with faster responses are at right. $\boldsymbol{D}$, Each bipolar cell receptive field was used in a separate model of the $0 M S$ response $(\boldsymbol{A})$. The quality of the model fit was measured by the correlation coefficient between predicted and observed OMS ganglion cell response $(\boldsymbol{B})$. The high speed cutoff of the bipolar cell was measured by the speed at which the sensitivity falls to $90 \%$ of the peak value (C). Here, the model quality is plotted against the high speed cutoff. The dotted line indicates the correlation coefficient calculated between ganglion cell responses to repeated jittering stimuli.

response varied greatly in accuracy: from $r=-0.25$ to $r=0.65$. A bipolar cell's upper speed cutoff, in turn, was a very sensitive indicator of whether it would generate a useful model (Fig. 5D). Those cells sensitive to the highest speeds (cutoff above $\sim 300$ $\mu \mathrm{m} / \mathrm{s})$ produced an accurate prediction $(r=0.61 \pm 0.02,4$ cells $)$, whereas the others did not $(r=0.1 \pm 0.09,7$ cells $)$. This suggests that the OMS circuitry makes selective use of the fastest bipolar cell types.

Interestingly, in addition to OFF-type bipolar cells, an ONtype bipolar cell was encountered with a receptive field appropri- ate to predict the OMS ganglion cell response (Fig. 5C,D). Although OMS ganglion cells in the salamander are dominated by OFF-type input (Ölveczky et al., 2003), they also receive some input from the ON pathway (Geffen et al., 2007). Thus, ON bipolar cells may well contribute to the response of OMS ganglion cells.

\section{Suppression of responses by background motion}

To measure how object and background motion are integrated at the level of ganglion cell synaptic input, we recorded membrane potential responses from an OMS ganglion cell while presenting either differential motion or global motion (Fig. 6). As observed previously, spiking was almost completely suppressed by global motion. In addition, the subthreshold membrane potential fluctuations were smaller under global motion, decreasing to a fraction of $0.45 \pm 0.08$ ( 5 cells) of their value during differential motion (Fig. 6B). However, there were no large IPSPs as might result from strong hyperpolarizing inhibition, and the decrease in response was consistent with either shunting or presynaptic inhibition. OMS ganglion cell responses were very homogeneous, in that each cell's intracellular recording was highly correlated to the average OMS cell response ( $r=$ $0.78 \pm 0.03,7$ cells).

\section{The effects of background motion on interneurons}

According to the working model of Figure $1 E$, when object and background regions experience the same motion trajectory, the ganglion cell receives inhibitory input from amacrine cells in the background region that is synchronous with excitatory input from the central object region. Thus, we inspected the responses of various inhibitory interneurons to a jittering background, and compared their timing to the responses of OMS ganglion cells under local motion with the same trajectory (Fig. $6 C-H)$. Among these recordings, the response of a polyaxonal amacrine cell type was appropriately timed to mediate suppression from the background region: its depolarizations were closely synchronized to those of the OMS ganglion cell (Fig. 6D). The correlation coefficient between a polyaxonal amacrine cell and an OMS ganglion cell responding to the same stimulus trajectory was $0.63 \pm$ 0.03 ( 7 cells), compared with 0.71 for repeats of an identical stimulus to a ganglion cell. Like OMS ganglion cells, polyaxonal amacrine cells were also very homogeneous; each cell's response was very similar to the average response ( $r=0.65 \pm 0.01,7$ cells $)$. In contrast, a different amacrine cell type, characterized by a slow ON-OFF response, produced depolarizations at the wrong times (Fig. $6 E$ ). Its signal had a correlation coefficient of only $0.13 \pm$ 

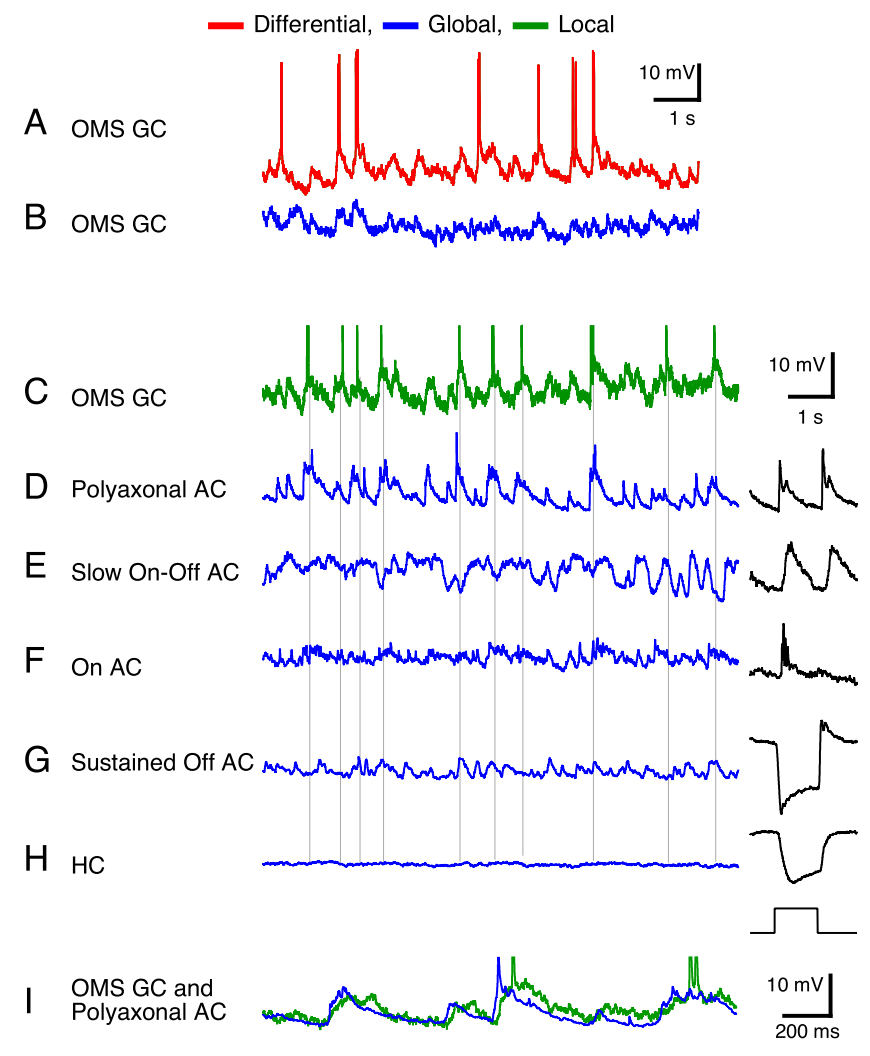

Figure 6. Signals of inhibitory interneurons during the OMS response. $\boldsymbol{A}, \boldsymbol{B}$, Intracellular recording from an OMS ganglion cell responding to differential motion or global motion. $\mathbf{C}-\boldsymbol{H}$, Response of an OMS ganglion cell and a panel of different inhibitory interneurons to the same motion trajectory: local motion for the OMS ganglion cell, and global motion for the inhibitory interneurons (different trajectory from panels $\boldsymbol{A}$ and $\boldsymbol{B}$ ). Vertical lines indicate action potentials of the OMS ganglion cell. Right, Response of the same neuron to a periodic stimulus, used to characterize the cell type: a contrast-reversing grating in $\boldsymbol{D}$ and $\boldsymbol{E}$, and a uniform field flash in $\boldsymbol{F}-\boldsymbol{H} . \boldsymbol{I}$, Expanded time scale comparing the polyaxonal amacrine cell response to global motion with the OMS ganglion cell response to local motion. $\mathrm{AC}$, Amacrine cell; $\mathrm{GC}$, ganglion cell; $\mathrm{HC}$, horizontal cell.

0.06 ( 6 cells) with the OMS cell depolarizations. Other amacrine cell types (Fig. $6 F, G$ ) also produced unrelated signals with correlations ranging from -0.10 to 0.29 ( 8 cells). Horizontal cells, of which the salamander also has multiple types, showed virtually no response to the jittering grating (Fig. $6 \mathrm{H}$ ) (4 cells), and thus are unlikely to contribute to suppression from the background region.

Based on this survey, the polyaxonal amacrine cell (Fig. 6D) appears to be a plausible candidate to transmit inhibition from the background region. Indeed the detailed timing of its depolarizations would enable an effective suppression of excitatory input to the OMS ganglion cell (Fig. 6I). By computing the crosscorrelation between the polyaxonal amacrine cell response to global motion and the OMS ganglion cell response to local motion of the same trajectory, we found that the amacrine cell preceded the ganglion cell by $26 \pm 7 \mathrm{~ms}$ ( 6 cell pairs; see Materials and Methods). This fits well with previous results indicating that the polyaxonal amacrine cell membrane potential precedes the suppression of OMS ganglion cell spiking by $\sim 25 \mathrm{~ms}$ (Ölveczky et al., 2003). Its broad output arborization would allow for rapid inhibition over long distances. Judging from experience in other species, there may well exist multiple kinds of amacrine cells with polyaxonal morphology, but in our survey so far all such amacrines were correlated to the OMS ganglion cells. For brevity, we will refer to these amacrines simply as "polyaxonal," bearing in mind that they are also identified by the time course of their motion response.

To further understand the interaction of signals from bipolar, amacrine, and ganglion cells, we used a different stimulus that clearly separates the effects of the center and surround regions (Fig. 7). Here the object grating and the background grating each moved back and forth in short $40 \mu \mathrm{m}$ steps every $1 \mathrm{~s}$. In the global motion condition, the two gratings stepped synchronously, whereas under differential motion they stepped in alternation (Fig. 7A). This stimulus distills the essential ingredients of the random jitter stimulus: brief periods of acceleration whose timing was either identical or different between object and background region. We recorded the responses of bipolar, OMS ganglion, and polyaxonal amacrine cells in the region of the object grating.

OMS ganglion cells produced a transient depolarization on every step of the object grating (Fig. $7 B$ ). Under global motion, this depolarization was considerably smaller than under differential motion, where the depolarizations led to spikes (amplitude ratio global $/$ differential $=0.52 \pm 0.03,4$ cells). Steps of the background region alone caused virtually no response, either depolarizing or hyperpolarizing (amplitude ratio background/object $=$ $0.04 \pm 0.05,4$ cells $)$.

We recorded from fast, transient OFF bipolar cells that yielded an accurate prediction of the OMS ganglion cell response when inserted into the model of Figure $5 \mathrm{~A}$ (see Materials and Methods). The dynamics of these bipolar cells resemble those described previously (Wu et al., 2000) for cells that arborize in the OFF sublamina near the middle of the inner plexiform layer (Fig. $2 A)$. Such a bipolar cell depolarized when a dark bar of the object grating stepped into its receptive field center (Fig. 7C). These depolarizations had very similar magnitude under global and differential motion (ratio global/differential $=0.93 \pm 0.02,7$ cells). This shows that bipolar cell excitation, as measured at the soma, is not suppressed by global motion. On the reverse step of the object grating, bipolar cells hyperpolarized, with a somewhat slower time course than in the preceding depolarization. This is likely a result of light adaptation, which makes for more sluggish responses at lower luminance (Naka et al., 1979). Finally, during differential motion, bipolar cells incurred brief hyperpolarizations on every step of the background grating (ratio background/ object $=0.34 \pm 0.05,7$ cells). This input was identical for steps of either sign, and thus must derive from an inhibitory interneuron with rectified responses. Horizontal cells are an unlikely source, because they have largely linear properties and hardly respond at all to these fine gratings (Fig. $6 \mathrm{H}$ ). Alternatively, this signal may derive from amacrine cells that inhibit the bipolar cell synaptic terminal, close to the site of transmission but at some electrotonic distance from the soma. This could help explain why the hyperpolarizing signals in somatic recordings are small (Fig. 7C), especially in the global motion condition, whereas the synaptic input to ganglion cells is strongly suppressed (Fig. 7B).

A typical polyaxonal amacrine cell with receptive field in the object region was strongly depolarized by movement of the object grating (Fig. 7D). Surprisingly, these amacrine cells showed a substantial depolarizing response also to movement in the background region (amplitude ratio background/object $=0.45 \pm$ $0.08,12$ cells). The linear receptive field of these cells is relatively small, consistent with a dendritic field of $\sim 200 \mu \mathrm{m}$ radius (Fig. $2 C$ ), and is contained entirely within the object region. In addition, however, polyaxonal amacrine cells show extensive tracer coupling, at least in mammalian retinas (Völgyi et al., 2001; 
A

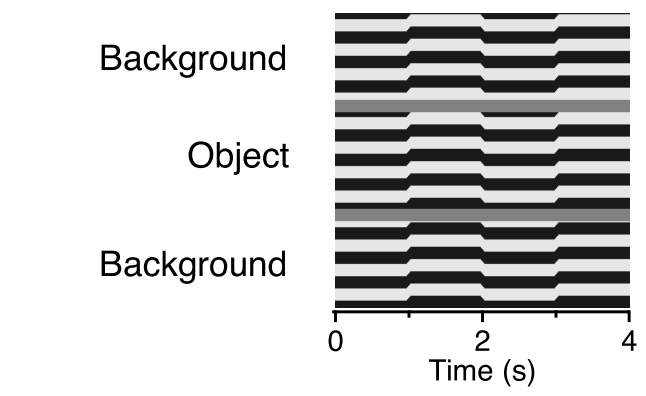

B

OMS ganglion cell

C Bipolar cell
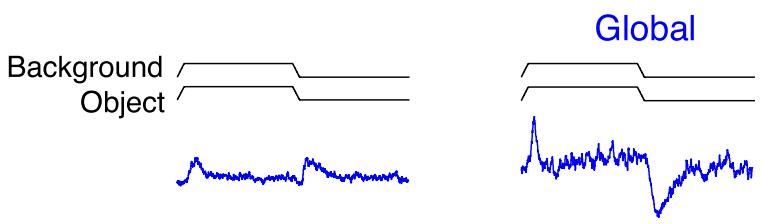

Differential
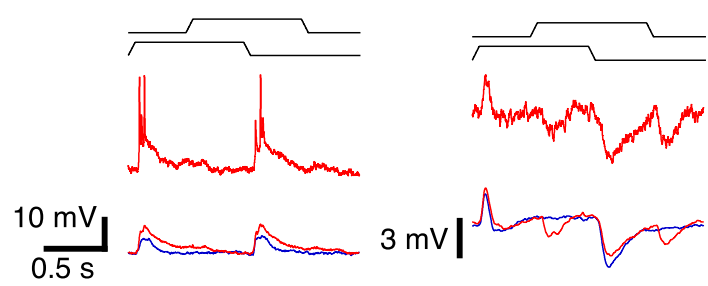

$3 \mathrm{mV}$

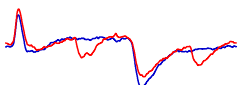

$30 \mathrm{mV} \mid$

Figure 7. Convergence of signals from object and background. Periodic jitter stimuli were composed of an object and background grating shifting back and forth $40 \mu \mathrm{m}$ every $1 \mathrm{~s}$. $A$, Space-time plot as in Figure $1 B$. The two gratings were shifted in synchrony for global motion and in alternation for differential motion. $\boldsymbol{B}-\boldsymbol{D}$, Membrane potential responses to periodic jitter. First row, Global motion. Second row, Differential motion. Third row, Average of 15 responses under each condition. $\boldsymbol{B}, 0 \mathrm{MS}$ ganglion cell. The third row shows the average of the subthreshold potential after spikes were removed. $C$, Fast, transient 0 FF-type bipolar cell. $\boldsymbol{D}$, Polyaxonal amacrine cell. All these neurons had a receptive field center in the object region.

Wright and Vaney, 2004). Thus it is possible that a weak excitatory input arrives through electrical synapses from distant polyaxonal amacrine cells, whose contribution is strong under global motion, when the population in the entire background region is driven in synchrony. Under differential motion, only the amacrines in the object region are synchronized with the OMS cell, and their action alone is clearly not sufficient to silence OMS cell firing (Fig. 7B, bottom).

\section{The role of polyaxonal amacrine cells}

The observed correlation of signals from polyaxonal amacrines and OMS cells is suggestive, but does not demonstrate a functional connection. To directly test for an inhibitory interaction, we recorded from a polyaxonal amacrine cell intracellularly while simultaneously recording from the ganglion cell population with a multielectrode array. A contrast-reversing grating was used to stimulate the ganglion cells. Simultaneously, we injected depolarizing current into the amacrine cell and measured whether that suppressed the ganglion cell's light response. By this measure, polyaxonal amacrine cells clearly inhibited the light response of OMS ganglion cells (by $17 \%$ on average), but not of other types of ganglion cells (Fig. 8 B,C). This effect was smaller than the complete suppression that occurs during global motion, presumably because it involved injection of just a single polyaxonal amacrine cell.
D Amacrine cell
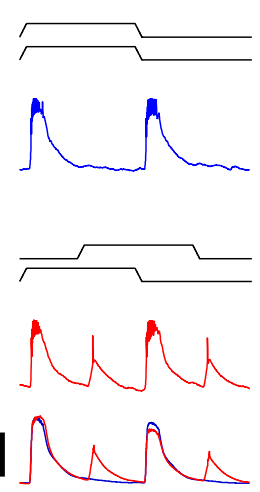

Given the fine laminar organization of the inner plexiform layer, one expects a priori that any given ganglion cell type should interact with only a small fraction of amacrine cells. Thus the positive finding of a connection between OMS ganglion cells and polyaxonal amacrines is significant. Nevertheless, we tested whether OMS ganglion cells are somehow particularly promiscuous, by injecting current into a different type of amacrine with slow $\mathrm{ON}-\mathrm{OFF}$ responses (Fig. 6E). This amacrine cell type inhibited certain non-OMS cells but had no effect on OMS cells (Fig. 8D,E). This demonstrates that the OMS ganglion cell derives its inhibitory input with some selectivity from polyaxonal amacrine cells. Vice versa, the polyaxonal amacrine cell targets its inhibitory output selectively to OMS ganglion cells, perhaps directly or via intervening neurons. This reinforces the precision of wiring in the inner plexiform layer, where many types of amacrine and bipolar cells are connected in specific subcircuits to a dozen types of ganglion cells (Roska and Werblin, 2001).

\section{Model of object motion sensitivity}

These results were assembled into a full model of differential motion sensitivity (Fig. 9). To predict the response of polyaxonal amacrine cells in the background region, an identical subunit model was used for the excitatory input of OMS ganglion cells (Fig. 5). As expected from the observation that polyaxonal amacrine cells and OMS ganglion cells have synchronous responses to identical motion trajectories (Fig. 6C,D), this model predicted the amacrine response accurately (Fig. 9B), yielding a correlation between the actual and predicted response of $r=0.73$.

To predict the response of an OMS ganglion cell to differential motion, amacrine inhibition from the background was combined with bipolar input from the object region before the stage of rectification, representing inhibition as observed at the presynaptic terminal (Fig. 7C). We used a divisive form of inhibition, in which the depolarization of the amacrine cell scales down the bipolar cell synaptic output (see Materials and Methods). This model produced accurate predictions of the OMS cell's response to differential motion (Fig. 9C). The best fits $(r=0.65)$ were obtained when the strength of inhibition was chosen to scale the bipolar output by at most a factor of 0.49 . This corresponds well to the $\sim 50 \%$ reduction in depolarization seen in the OMS ganglion cell during global motion versus differential motion (Figs. $6 A, B, 7 B)$.

\section{Discussion}

This study provides a circuit explanation for a prominent computation in the retina: the detection of differential motion. Transient responses, small spatial subunits, strong rectification, long axonal projections, and specific functional connections combine to emphasize object motion while rejecting background motion resulting from eye movements. We subjected a basic working 
A

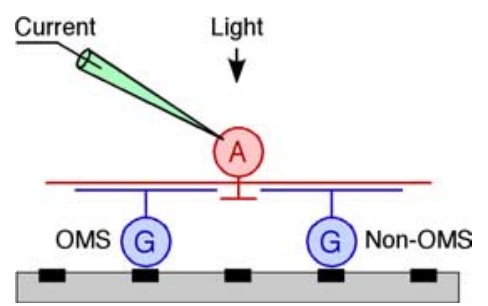

$\mathrm{GC}$ response

Inhibition

Light

Light + current

\section{B Polyaxonal AC to $\mathrm{OMS}$ GC}

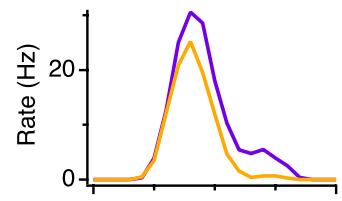

\section{Polyaxonal AC \\ Non-OMS GC}
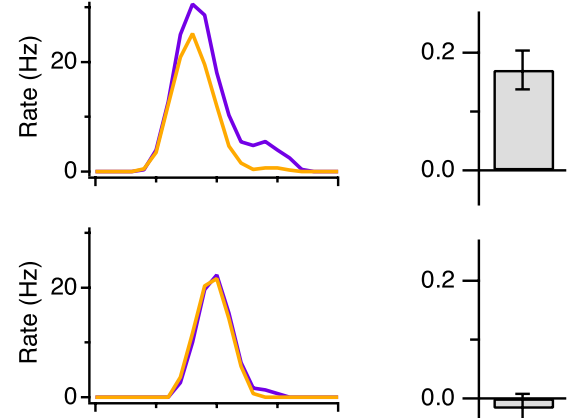

Slow On-Off AC to $\mathrm{OMS}$

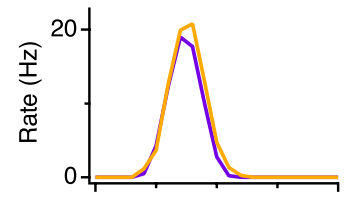

\section{E Slow On-Off AC Non-OMS GC}

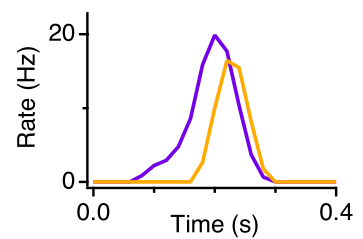

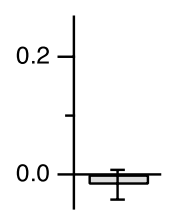
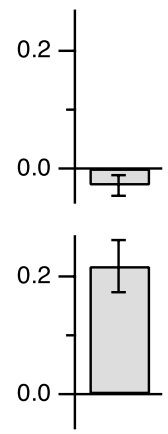

Figure 8. Polyaxonal amacrine cells selectively suppress OMS ganglion cells. $A$, Schematic diagram of experiment. Contrast reversal of a grating was used to visually stimulate the retina either alone or synchronous with a depolarizing current pulse $(500 \mathrm{pA}, 0.5 \mathrm{~s})$ delivered intracellularly to an amacrine cell. Spiking activity from OMS and non-OMS ganglion cells (G) was recorded with a multielectrode array. Responses were analyzed from ganglion cells within 200 $\mu \mathrm{m}$ of the amacrine cell (A). $B, C$, Results from current injection into a polyaxonal amacrine cell (AC). B, Left, Average firing rate over 30 trials of an $0 \mathrm{MS}$ ganglion cell (GC) responding to the visual stimulus with and without the current pulse. Trials for the two conditions were interleaved. Right, Fractional inhibition of ganglion cell firing by the current pulse (mean \pm SEM, 10 $\mathrm{GCS}, 3 \mathrm{ACs})$. C, Left, Same as $\boldsymbol{B}$ for a non-OMS OFF-type ganglion cell. Right, Fractional inhibition of non-0MS ganglion cells ( $13 \mathrm{GCS}, 3 \mathrm{ACS}$ ). $\boldsymbol{D}, \boldsymbol{E}$, Results from current injection into a slow ON-OFF amacrine cell, presented as in $\boldsymbol{B}$ and $\boldsymbol{C}$. $\boldsymbol{D}$, Left, $0 \mathrm{MS}$ ganglion cell light response with and without the current pulse. Right, Fractional inhibition of OMS ganglion cells ( $10 \mathrm{GCS}, 3 \mathrm{ACS}$ ). $\boldsymbol{E}$, Left, Same as $\boldsymbol{D}$ for a non-OMS OFF-type ganglion cell. Right, Fractional inhibition of non-OMS ganglion cells (10 GCs, $3 \mathrm{ACs})$.

hypothesis of the circuit (Fig. $1 E$ ) to many experimental tests, and elaborated on this model as summarized in Figure 10. Probing the various interneurons intracellularly fleshed out the components of the circuit and uncovered new aspects of processing. The answers to the four questions posed at the outset are as follows: (1) The small subunits are bipolar cells. Among bipolars, there is a range of response kinetics, and only the fastest ones account for the function of this circuit. (2) The excitatory ganglion cell input is rectified, whereas the bipolar cell response is linear. This places the rectification at the bipolar-to-ganglion cell

synapse. (3) The inhibition is likely presynaptic on the bipolar terminal. This implies that differential motion is computed one neuron earlier and across a smaller spatial scale than previously proposed (Ölveczky et al., 2003). (4) Among all the interneurons tested, only the polyaxonal amacrine cells have the response properties required to implement inhibition from global motion. They integrate motion signals from beyond the dendritic tree, perhaps via electrical coupling. Horizontal cells are not involved in the computation. Furthermore, the polyaxonal amacrine cells do indeed suppress the responses of OMS ganglion cells, but not other ganglion cell types. In addition, we found the following: (5) Because polyaxonal amacrine cells are not themselves suppressed, they receive input from a different set of bipolar cell terminals than the OMS cells. (6) Finally, a mathematical model of the proposed circuit, when supplied with the measured signals from interneurons, can predict the responses at each stage in the circuit in a quantitative manner.

\section{Summary of signal flow}

An essential part of the computation is the nonlinear spatial summation over small subunits in the ganglion cell receptive field center. Among all the interneurons sampled in our experiments, bipolar cells are the only ones with receptive field properties that match the requirements for this role. The retina contains many kinds of bipolar cells, which differ both in morphology and in the time course of the light response (Burkhardt and Fahey, 1998; DeVries, 2000; Wu et al., 2000; Ghosh et al., 2004). The OMS circuitry involves only certain of these neurons; in particular, the dynamic properties of the OMS response are consistent only with the fastest among the bipolar cells we sampled (Fig. 5).

Motion in the object region drives these bipolar cells, and their outputs are rectified before summation by the ganglion cell. We showed that this rectification occurs after the bipolar cell soma, not at the photoreceptor-bipolar cell synapse, counter to a proposal made for mammalian Y-cells (Demb et al., 2001).

Motion in the background region drives, among others, a population of polyaxonal amacrine cells. The response of these neurons matches almost perfectly that of the OMS ganglion cell to the same trajectory (Fig. 6). It appears likely, therefore, that the polyaxonal amacrines are driven by a similar network of rectified bipolar cell inputs (Fig. 10). In addition, these amacrine cells may be coupled electrically, because they receive excitatory input from far beyond the dendritic field (Fig. 7). Furthermore, we showed by direct single-neuron stimulation that polyaxonal amacrine cells are wired to suppress the visual response of OMS ganglion cells (Fig. 8). In principle, this may occur through a direct inhibitory synapse or through presynaptic inhibition of a bipolar terminal (Cook and McReynolds, 1998). Our observations favor the latter (Fig. 10), because the inhibition can be detected in the bipolar cell signal, whereas ganglion cells show no overt inhibitory potentials (Fig. 7). Further support for presynaptic inhibition comes from a recent study on adaptation in the OMS response (Ölveczky et al., 2007). We found this effect from polyaxonal amacrines to be specific to the OMS ganglion cell type (Fig. 8). It is encouraging to find that a single amacrine cell has a measurable effect on a nearby ganglion cell, and paired recordings of this type will be invaluable in unraveling the various subcircuits of the retina (Geffen et al., 2007). A further important aspect of the polyaxonal amacrine network is the speed of propagation of axon impulses, to ensure that the inhibition can arrive fast enough to suppress excitatory input. It appears that propagation and inhibitory synaptic transmission occur within $\sim 25 \mathrm{~ms}$ (Fig. 6I) (Ölveczky et al., 2003). 
A

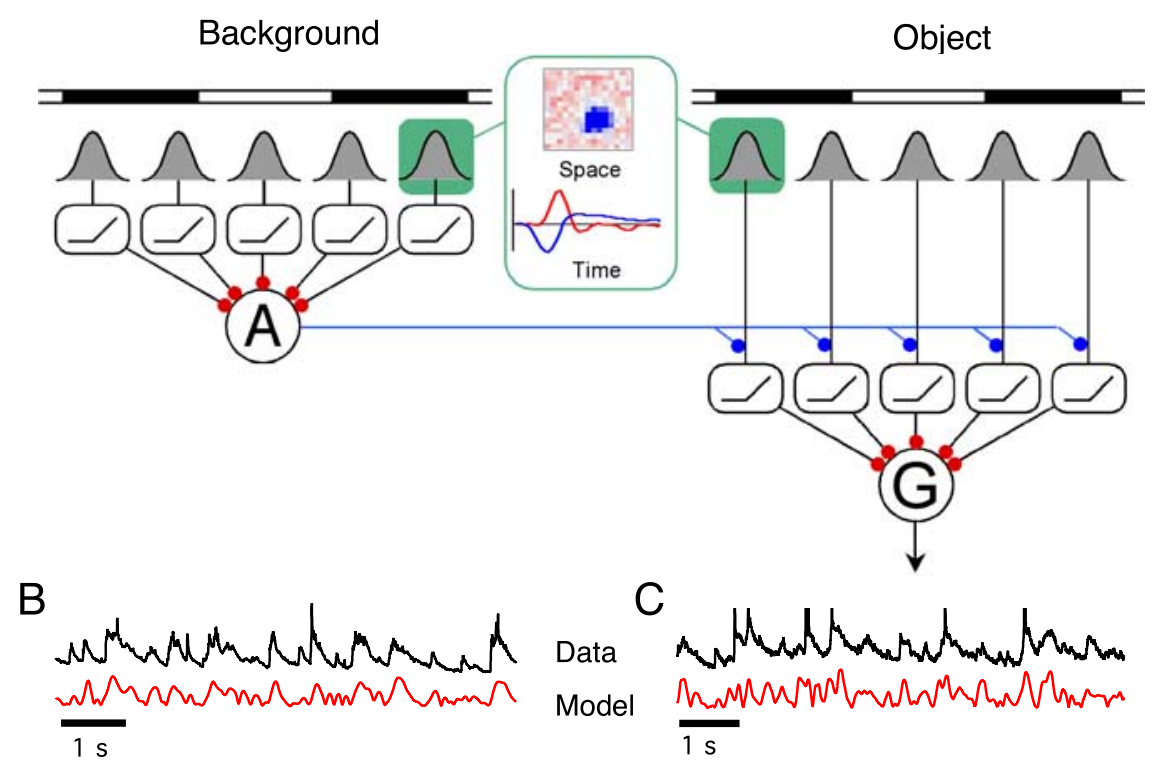

Figure 9. Model of object motion sensitivity. A, Amacrine and ganglion cells each sum the rectified output of many linear bipolar cells. Amacrine inhibition is delivered to the output of the bipolar cell before rectification, for example, at the bipolar cell presynaptic terminal. The output of the amacrine cell scales the bipolar output by a factor ranging between $\sim 0.5$ and 1 (see Materials and Methods). $\boldsymbol{B}$, Comparison of actual and model amacrine cell membrane potential response to background motion. C, Comparison of actual and model ganglion cell membrane potential response to differential motion. The motion trajectory is different from that in $\boldsymbol{B}$.

\section{Background}

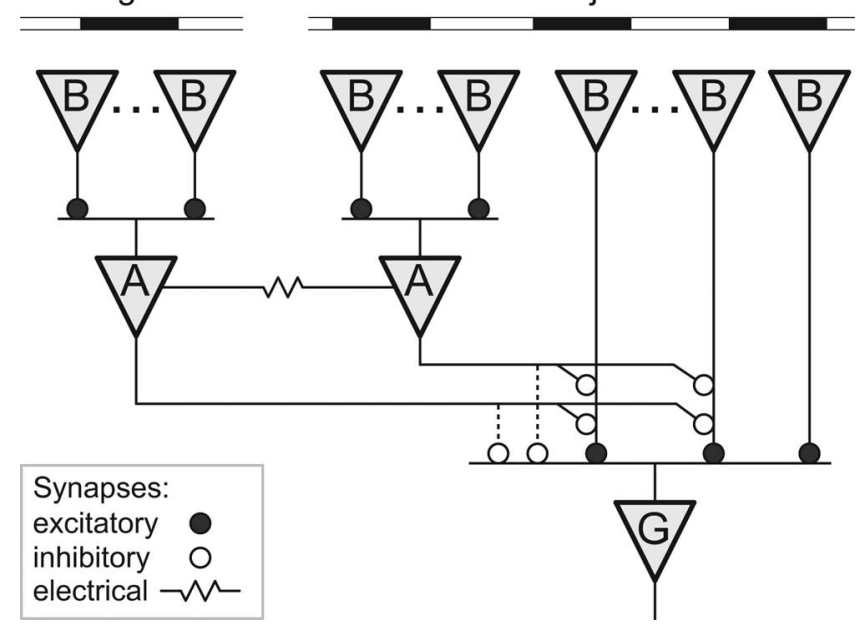

Figure 10. A circuit for object motion sensitivity. Proposed neural circuitry underlying the OMS response, linking bipolar cells (B), polyaxonal amacrine cells (A), and OMS ganglion cells (G). The bipolar cells have an OFF-type transient response, and their synapses are rectifying. The polyaxonal amacrine cells have a restricted dendritic field that pools excitation from many bipolars and are probably coupled electrically to more distant amacrines in the population. The OMS ganglion cell also pools over many bipolars, but their terminals are inhibited by the polyaxonal amacrine cells. Direct, shunting inhibition of the OMS ganglion cell may also exist. Note that the bipolar cell synapses onto amacrines do not receive presynaptic inhibition.

\section{An algorithm for differential motion detection}

At a basic level, the comparison of motion of the object and the background is performed through the time domain (Fig. 1E). The motion trajectories of both the object and background are converted into a sequence of depolarizing pulses. Then the two pulse sequences are compared. If the timing matches, the ganglion cell remains silent; otherwise, it fires.
This algorithm for computing differential motion owes its success to several special constraints in the ecology of vision. First, the global motion signal is driven by fixational eye movements. The randomwalk nature of this image trajectory (Engbert and Kliegl, 2004) includes frequent accelerations, which, when filtered through the biphasic temporal receptive field of bipolar cells, lead to a pulsatile output. Transmission to the ganglion cell seems to apply a high threshold (Fig. 5), resulting in a sparse sequence of excitatory pulses, which allows for a selective temporal comparison between the sequences derived from the object and the background. Only an object trajectory identical to that of the background is silenced; others are encoded faithfully, except for occasional coincidences between eye motion and object motion. This would not be possible if the background image motion were smooth with constant velocity.

Second, the algorithm compares only the speed of motion of the object and the background, not the direction. Indeed, we showed that the OMS ganglion cells are duly suppressed even when object and background move in opposite direction but with the same instantaneous speed (Ölveczky et al., 2003). During natural vision, a measurement of speed is sufficient to distinguish eye from object velocities, because it is highly unlikely that the eye and the object conspire to produce an image speed matching that of the background.

Thus ecological circumstances permit a differential motion algorithm that never computes the direction of motion. A parallel can be found in the jamming avoidance response of wave-type electric fish, whose algorithm computes the difference in the frequency of two signals without ever encoding either frequency (Heiligenberg, 1989). Again, a combination of ecological constraints makes this a viable approximation. However, it should be noted that differential motion is computed again at later stages of the visual system, for example in the bird's optic tectum (Frost and Nakayama, 1983) and in area MT of visual cortex (Born and Tootell, 1992). Those computations are indeed selective for direction, and furthermore, they work well with smooth trajectories of global movement. Presumably they serve a different function, for example, the analysis of optic flow generated by observer motion.

\section{Selectivity and invariance}

The object motion-sensitive neurons of the retina show a high selectivity for differential motion, and at the same time almost complete invariance with regard to the spatial pattern that is moving. These are, of course, highly desirable properties for a general detector of movement within the visual scene. From a broader viewpoint, the combination of selectivity and invariance is commonly regarded as a hallmark of sophisticated computation in higher stages of the brain, for example, in positioninvariant face-selective neurons (Hung et al., 2005). It is instructive to see how it comes about in the experimentally tractable circuits of the retina.

Pattern invariance is computed early in the circuit. It arises 
already within the background region, before any comparison to motion in the object region. Essentially, it is guaranteed by the pooling over rectified bipolar cells within the dendritic field of a polyaxonal amacrine cell (Fig. 10). This nonlinear summation makes the depolarizations of the amacrine cell largely independent of pattern phase or spatial frequency (Hochstein and Shapley, 1976; Ölveczky et al., 2003). The selectivity for differential motion arises one synapse later, when signals from the object and background regions converge, and the timing of excitation and inhibition are compared. This may occur at the OMS ganglion cell, or more likely at the bipolar cell terminal (Fig. 10). Pattern invariance within the object region is again accomplished by pooling within the dendritic field of the OMS ganglion cell.

This scheme differs significantly from the proposed algorithms in other neural systems, where selectivity is computed first. For example, complex cells in the primary visual cortex are quite selective for the orientation of a line, but not for the line's position. In the classic Hubel-Wiesel model, it is assumed that they function by pooling over many simple cells, each of which is selective for both orientation and position (Hubel and Wiesel, 1962). Similarly, the owl's auditory midbrain contains neurons that are selective for the difference in latency of a sound at the two ears, but not for the frequency of the sound. It is thought that these neurons pool over many presynaptic cells, each of which is tuned for interaural time difference, but also selective for a certain frequency (Konishi, 2003). Our study shows that this is not the only route: in the case of differential motion detection, stimulus generalization begins early in the circuit, and the selection of a specific stimulus quality occurs one synapse later.

\section{References}

Baccus SA, Meister M (2002) Fast and slow contrast adaptation in retinal circuitry. Neuron 36:909-919.

Born RT, Tootell RB (1992) Segregation of global and local motion processing in primate middle temporal visual area. Nature 357:497-499.

Burkhardt DA, Fahey PK (1998) Contrast enhancement and distributed encoding by bipolar cells in the retina. J Neurophysiol 80:1070-1081.

Cook PB, McReynolds JS (1998) Lateral inhibition in the inner retina is important for spatial tuning of ganglion cells. Nat Neurosci 1:714-719.

Costa LF, Velte TJ (1999) Automatic characterization and classification of ganglion cells from the salamander retina. J Comp Neurol 404:33-51.

Demb JB, Zaghloul K, Haarsma L, Sterling P (2001) Bipolar cells contribute to nonlinear spatial summation in the brisk-transient $(\mathrm{Y})$ ganglion cell in mammalian retina. J Neurosci 21:7447-7454.

DeVries SH (2000) Bipolar cells use kainate and AMPA receptors to filter visual information into separate channels. Neuron 28:847-856.

Engbert R, Kliegl R (2004) Microsaccades keep the eyes' balance during fixation. Psychol Sci 15:431-436.
Frost BJ, Nakayama K (1983) Single visual neurons code opposing motion independent of direction. Science 220:744-745.

Geffen MN, de Vries SE, Meister M (2007) Retinal ganglion cells can rapidly change polarity from Off to On. PLoS Biol 5:e65.

Ghosh KK, Bujan S, Haverkamp S, Feigenspan A, Wässle H (2004) Types of bipolar cells in the mouse retina. J Comp Neurol 469:70-82.

Heidelberger R, Matthews G (1992) Calcium influx and calcium current in single synaptic terminals of goldfish retinal bipolar neurons. J Physiol 447:235-256.

Heiligenberg W (1989) Coding and processing of electrosensory information in gymnotiform fish. J Exp Biol 146:255-275.

Hochstein S, Shapley RM (1976) Linear and nonlinear spatial subunits in Y cat retinal ganglion cells. J Physiol 262:265-284.

Hubel DH, Wiesel TN (1962) Receptive fields, binocular interaction and functional architecture in the cat's visual cortex. J Physiol 160:106-154.

Hung CP, Kreiman G, Poggio T, DiCarlo JJ (2005) Fast readout of object identity from macaque inferior temporal cortex. Science 310:863-866.

Konishi M (2003) Coding of auditory space. Annu Rev Neurosci 26:31-55.

Manteuffel G, Plasa L, Sommer TJ, Wess O (1977) Involuntary eye movements in salamanders. Naturwissenschaften 64:533-534.

Masland RH (2001) The fundamental plan of the retina. Nat Neurosci 4:877-886.

Meister M, Pine J, Baylor DA (1994) Multi-neuronal signals from the retina: acquisition and analysis. J Neurosci Methods 51:95-106.

Naka KI, Chan RY, Yasui S (1979) Adaptation in catfish retina. J Neurophysiol 42:441-454.

Ölveczky BP, Baccus SA, Meister M (2003) Segregation of object and background motion in the retina. Nature 423:401-408.

Ölveczky BP, Baccus SA, Meister M (2007) Retinal adaptation to object motion. Neuron 56:689-700.

Roska B, Werblin F (2001) Vertical interactions across ten parallel, stacked representations in the mammalian retina. Nature 410:583-587.

Segev R, Puchalla J, Berry MJ 2nd (2006) Functional organization of ganglion cells in the salamander retina. J Neurophysiol 95:2277-2292.

Shapley RM, Victor JD (1979) Nonlinear spatial summation and the contrast gain control of cat retinal ganglion cells. J Physiol 290:141-161.

Skavenski AA, Hansen RM, Steinman RM, Winterson BJ (1979) Quality of retinal image stabilization during small natural and artificial body rotations in man. Vision Res 19:675-683.

Victor JD, Shapley RM (1979) The nonlinear pathway of Y ganglion cells in the cat retina. J Gen Physiol 74:671-689.

Völgyi B, Xin D, Amarillo Y, Bloomfield SA (2001) Morphology and physiology of the polyaxonal amacrine cells in the rabbit retina. J Comp Neurol 440:109-125.

Warland DK, Reinagel P, Meister M (1997) Decoding visual information from a population of retinal ganglion cells. J Neurophysiol 78:2336-2350.

Wright LL, Vaney DI (2004) The type 1 polyaxonal amacrine cells of the rabbit retina: a tracer-coupling study. Vis Neurosci 21:145-155.

Wu SM, Gao F, Maple BR (2000) Functional architecture of synapses in the inner retina: segregation of visual signals by stratification of bipolar cell axon terminals. J Neurosci 20:4462-4470. 